\title{
Urinary estrogen metabolites and breast cancer risk in Chinese population
}

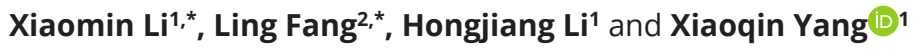 \\ ${ }^{1}$ Department of Breast Surgery, West China Hospital, Sichuan University, Chengdu, China \\ ${ }^{2}$ Department of Breast Surgery, Cheng Du Shang Jin Nan Fu Hospital, West China Hospital, Sichuan University, Chengdu, China
}

Correspondence should be addressed to X Yang: xiaoqinyang2019@outlook.com

*(X Li and L Fang contributed equally to this work)

\begin{abstract}
Background: In China, the association between estrogen metabolism and breast cancer risk and the differences in metabolic pattern between breast cancer patients and controls are poorly understood.

Methods: A total of 84 patients with invasive breast cancer and 47 controls with benign breast diseases were included in this study. Estrogen metabolites from their morning urine were determined by HPLC-MS/MS and evaluated in both groups, and the predictive value of each estrogen metabolite in the malignant group according to their menstrual status was analyzed.

Results: Urinary concentration of estrogen metabolites 2-hydroxyestrone (2-OHE1), 2-hydroxyestradiol (2-OHE2), 4-hydroxyestradiol (4-OHE2), 4-methoxyestrone (4-MeOE1), and $16 \alpha$-hydroxyestrone were lower in postmenopausal patients with breast cancer, compared with benign controls. In logistic regression model, breast cancer risk increased with the decline in the levels of 4-OHE2 and 4-MeOE1. In premenopausal patients, a difference in the level of 2-OHE2 was observed between both groups, and 2-OHE2 was found to have predictive value for breast cancer. Additionally, urinary 2-OHE2 level in premenopausal hormone receptor positive $(\mathrm{HR}+)$ patients was considerably higher compared with hormone receptor negative patients.

Conclusions: We found that lower urinary levels of 4-OHE2 and 4-MeOE1 had predictive value for breast cancer, and higher 2-OHE1 were associated with $\mathrm{HR}+$ breast cancer in premenopausal women.
\end{abstract}

\author{
Key Words \\ - breast cancer \\ - liquid chromatography \\ tandem mass \\ spectrometry \\ - estrogen metabolism \\ - hormone receptor \\ - estrogen receptor
}

\section{Introduction}

Breast cancer is a malignant tumor that occurs in the mammary gland. It is the leading female malignant tumor, posing a major threat to women's health globally. However, the incidence of breast cancer worldwide, including China, has gradually increased recently $(1,2)$.

In patients with breast cancer, abnormalities occur in estrogen metabolism, in particular in the level of estrogen and their metabolites. Hydroxylation of the carbon atoms at positions 2, 4, and 16 of the steroid ring of estrogen produces a cascade of metabolites with diverse biological properties, such as 2-hydroxyestrone (2-OHE1), 4-hydroxyestrone (4-OHE1), and 16 $\alpha$-hydroxyestrone (16 $\alpha$-OHE1). These hydroxylated metabolites can be further methylated into less toxic methoxy derivatives or oxidized into mutagenic quinone adducts $(3,4,5)$. Estrogen and their metabolites are considered to be one of the most important factors affecting breast cancer risk $(6,7)$. By binding to its corresponding estrogen receptor (ER), estrogen can activate the receptor signaling pathways to promote cell growth, proliferation, and endometrial

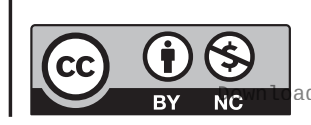

This work is licensed under a Creative Commons Attribution-NonCommercial 4.0 International License. ded from Bioscientifica.com at 04/26/2023 07:06:20AM 
hyperplasia, ultimately leading to the occurrence of cancer $(8,9,10)$. Estrogen metabolites cause noticeably different effects: 2-OHE1 and 2-hydroxyestradiol (2-OHE2), as tumor suppressors, can inhibit breast cancer cell growth and proliferation by reducing the binding affinity to the ER, in contrast to $16 \alpha$-OHE1 which has a very strong affinity to the ER with potential genotoxic damage $(11,12$, 13, 14, 15).

Previous epidemiological studies of estrogen metabolism have been limited and were conducted using RIA and ELISA which have poor specificity, accuracy, and/or reproducibility (16, 17, 18, 19). HPLC coupled with MS makes more sensitive, specific, and accurate epidemiological studies possible $(20,21,22,23$, $24,25,26)$.

Recently, we developed a rapid quantitative HPLC-MS/MS method that can simultaneously detect estrogen and their metabolites with high specificity (27). In this study, we used this method to determine estrogens and estrogen metabolites in the urine of patients with breast cancer and fibroadenoma, a benign breast disease. The association between ER status and estrogen metabolism in breast cancer was also analyzed.

\section{Methods}

\section{Patients and samples}

From January 2019 to September 2019, we collected morning urine samples from 84 invasive breast cancer patients and 47 breast fibroadenoma patients, in the Department of Breast Surgery, West China Hospital, Sichuan University. The inclusion criteria were as follows: (1) female patients aged 18-75 years old; (2) diagnosed with primary invasive breast cancer by core needle biopsy or diagnosed with fibroadenoma clinically; (3) have not received medical treatment of exogenous estrogen or progestin; (4) have not received systemic breast cancerrelated treatment; and (5) have normal liver and kidney function. We excluded patients receiving exogenous estrogen or progestin or systemic treatment, exhibiting abnormal liver or kidney function, or diagnosed with another cancer, with endocrine disease, with ovary disease or pregnancy.

The morning urine samples were collected at the time of diagnosis for postmenopausal patients or on the 7th day in the menstrual cycle for premenopausal patients. ER positivity or progesterone receptor positivity was defined as both $\geq 1 \%$ positive tumor cells with nuclear staining.
The study was approved by the Ethics Commission of West China Hospital of Sichuan University, and every participant signed an informed consent.

\section{Laboratory assay}

In urine, endogenous estrogens (estradiol and estrone) and their metabolites are present primarily in a conjugated form. Based on the criteria previously described, prior to sample analysis, a hydrolysis step is required to release endogenous estrogens and their metabolites in urine. Glucuronide and sulfate moieties were removed, allowing for the measurement of total levels of each estrogen and estrogen metabolite.

HPLC-MS/MS analysis was performed using a LCMS-8050 Triple Quadrupole Liquid Chromatography Mass Spectrometry system (Shimadzu, Kyoto, Japan) to measure estrogens and metabolites in urine samples (27). Quantification of estrogens and metabolites was carried out using LabSolutions software (Shimadzu). Molar quantities were standardized to creatinine accordingly.

\section{Statistical analysis}

Data were analyzed using SPSS version 25.0 (IBM). The chi-squared test was used to assess the association between breast diseases and the clinicopathological parameters of patients. The Mann-Whitney $U$ test was applied for the comparison of estrogen metabolites between breast cancer and benign controls, and between patients who were hormone receptor (HR) positive or negative. Logistic regression was used to assess the association of estrogen metabolites that displayed significant differences between pairwise groups with breast cancer risk. The predictive value of estrogen metabolite for breast cancer was evaluated by receiver operating characteristic (ROC) curve.

\section{Results}

\section{Baseline characteristics of patients}

We analyzed 131 patients, including 84 diagnosed with invasive breast cancer and 47 diagnosed with breast fibroadenoma. The baseline characteristics of all patients are presented in Table 1, showing the association between the two groups in clinicopathological parameters. There were no significant differences between both groups in menstrual status and history of past illnesses (family history of breast cancer, history of smoking, or history

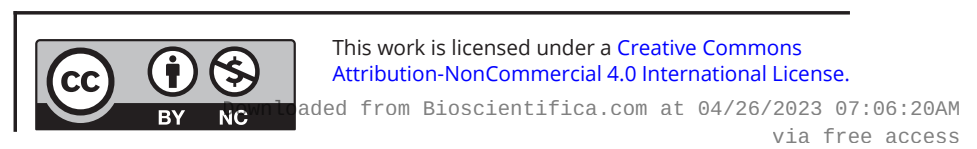


Table 1 Baseline characteristics.

\begin{tabular}{|c|c|c|c|c|c|}
\hline \multirow[b]{2}{*}{ Characteristic } & \multicolumn{2}{|c|}{ Cases } & \multicolumn{2}{|c|}{ Controls } & \multirow[b]{2}{*}{$\boldsymbol{P}$} \\
\hline & Number 84 & $\%$ & Number 47 & $\%$ & \\
\hline Age (years) & & & & & 0.005 \\
\hline$<55$ & 52 & 56.5 & 40 & 43.5 & \\
\hline$\geq 55$ & 32 & 82.1 & 7 & 17.9 & \\
\hline $\mathrm{BMI}\left(\mathrm{kg} / \mathrm{m}^{2}\right)$ & & & & & 0.003 \\
\hline$<25$ & 48 & 55.2 & 39 & 44.8 & \\
\hline$\geq 25$ & 36 & 81.8 & 8 & 18.2 & \\
\hline Menopause & & & & & 0.611 \\
\hline No & 39 & 61.9 & 24 & 38.1 & \\
\hline Yes & 45 & 66.2 & 23 & 33.8 & \\
\hline HR status & & & & & \\
\hline Positive & 66 & & & & \\
\hline Negative & 18 & & & & \\
\hline Molecular subtype & & & & & \\
\hline Luminal A BC & 17 & & & & \\
\hline Luminal B BC & 49 & & & & \\
\hline HER2-enriched & 10 & & & & \\
\hline TNBC & 8 & & & & \\
\hline $\begin{array}{c}\text { Family history of } \\
\text { breast cancer }\end{array}$ & & & & & 1.000 \\
\hline No & 78 & 63.9 & 44 & 36.1 & \\
\hline Yes & 6 & 66.7 & 3 & 33.3 & \\
\hline History of smoking & & & & & 1.000 \\
\hline No & 76 & 63.9 & 43 & 36.1 & \\
\hline Yes & 8 & 66.7 & 4 & 33.3 & \\
\hline $\begin{array}{l}\text { History of alcohol } \\
\text { consumption }\end{array}$ & & & & & 1.000 \\
\hline No & 77 & 64.2 & 43 & 35.8 & \\
\hline Yes & 7 & 63.6 & 4 & 36.4 & \\
\hline
\end{tabular}

Cases, invasive breast cancer; Controls, breast fibroadenoma; HR, hormone receptor; Luminal $A B C$, hormone receptor positive (ER and/or PR positive), HER2 negative, and Ki-67 low; Luminal B BC, hormone receptor positive (ER and/or PR positive), and either HER2 positive or HER2 negative with high levels of Ki-67; HER2-enriched, hormone receptor negative (ER and PR negative) and HER2 positive; TNBC, triple-negative breast cancer.

Bold indicates statistical significance, $P<0.05$. of alcohol consumption). We found that patients with increased age $(P=0.005)$ or BMI $(P=0.003)$ were more likely to have breast cancer.

\section{Estrogen metabolism in breast cancer and fibroadenoma patients}

Due to the decrease in the levels of estrogen metabolites following menopause, cases were divided into premenopausal and postmenopausal groups for further analysis. The urinary concentrations of estradiol and estrone (parent estrogens) and their estrogen metabolites were compared in pre- or postmenopausal patients with breast cancer and breast fibroadenoma, respectively, and are presented in Tables 2 and 3. In postmenopausal patients (Table 3$)$, the urinary levels of 2-OHE1 $(P=0.029)$, 2-OHE2 $(P=0.006), 4$-OHE2 $(P<0.001), 4$-methoxyestrone $(4-\mathrm{MeOE} 1)(P<0.001)$, and $16 \alpha-\mathrm{OHE} 1(P<0.001)$ in patients with breast cancer were remarkably lower compared with breast fibroadenoma counterparts. In premenopausal patients (Table 2), there was a significant difference in the urinary level of 2-OHE2 $(P=0.022)$ between the two groups.

From the logistic regression analysis (Fig. 1), we found that 4-OHE2 and 4-MeOE1 were independent predictors for breast cancer risk. Patients with $\leq 0.085 \mathrm{ng} / \mathrm{mg}$ urinary 4-OHE2 and $\leq 0.115 \mathrm{ng} / \mathrm{mg}$ urinary 4-MetOE1 had a 9.9 and $8.5 \%$ reduced risk of developing breast cancer, respectively, compared with their counterparts. ROC analysis revealed that the levels of urinary 2-OHE1, 2-OHE2, 4-OHE2, 4-MetOE1, and 16 $\alpha$-OHE1 in postmenopausal patients (Fig. 2) had predictive value for breast cancer, with the optimal cutoffs of $0.425,0.415,0.085,0.115$, and 0.345 , respectively.

Table 2 Estrogen metabolism in premenopausal patients.

\begin{tabular}{l}
\hline Estrogens and estrogen metabolites \\
\hline Parent estrogens \\
Estrone \\
Estradiol \\
2-Hydroxylation pathway \\
2-OHE1 \\
2-OHE2 \\
2-MeOE1 \\
4-Hydroxylation pathway \\
4-OHE1 \\
4-OHE2 \\
4-MeOE1 \\
16-Hydroxylation pathway \\
16 $\alpha$-OHE1 \\
Estriol \\
Total estrogens/estrogen metabolites
\end{tabular}

\begin{tabular}{c}
\hline Invasive breast cancer 50th (25th, 75th) \\
\hline $6.35(4.29,8.78)$ \\
$4.09(3.03,5.29)$ \\
$2.04(1.44,3.84)$ \\
$1.90(1.21,3.57)$ \\
$1.03(0.51,2.49)$ \\
$0.11(0,0.47)$ \\
$0.51(0.36,0.67)$ \\
$0.31(0.04,0.82)$ \\
$0.25(0,0.69)$ \\
$0(0,0.06)$ \\
$0(0,0.01)$ \\
$3.43(1.93,5.64)$ \\
$0.54(0.34,0.98)$ \\
$2.71(1.55,4.71)$ \\
$9.25(7.87,19.80)$
\end{tabular}

\begin{tabular}{c}
\hline Breast fibroadenoma 50th (25th, 75th) \\
\hline $4.45(3.09,8.59)$ \\
$4.32(2.79,8.01)$ \\
$2.81(1.54,4.54)$ \\
$3.11(1.86,6.19)$ \\
$1.49(0.56,2.62)$ \\
$0.73(0,1.44)$ \\
$0.58(0.34,0.92)$ \\
$0.62(0.11,1.58)$ \\
$0.34(0,1.43)$ \\
$0(0,0.18)$ \\
$0(0,0.01)$ \\
$4.11(2.15,10.42)$ \\
$0.68(0.31,2.22)$ \\
$3.11(1.63,8.02)$ \\
$10.17(8.90,23.45)$ \\
\hline
\end{tabular}

\begin{tabular}{c}
\hline $\boldsymbol{P}$ \\
\hline 0.420 \\
0.466 \\
0.305 \\
0.065 \\
0.484 \\
$\mathbf{0 . 0 2 2}$ \\
0.266 \\
0.152 \\
0.458 \\
0.113 \\
0.708 \\
0.298 \\
0.226 \\
0.396 \\
0.108 \\
\hline
\end{tabular}

Bold indicates statistical significance, $P<0.05$.

https://ec.bioscientifica.com

https://doi.org/10.1530/EC-21-0226 (c) 2021 The authors Published by Bioscientifica Ltd

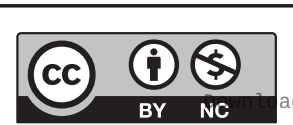

This work is licensed under a Creative Commons Attribution-NonCommercial 4.0 International License. ded from Bioscientifica.com at 04/26/2023 07:06:20AM via free access 
Table 3 Estrogen metabolism in postmenopausal patients.

\begin{tabular}{l}
\hline Estrogens and estrogen metabolites \\
\hline Parent estrogens \\
Estrone \\
Estradiol \\
2-Hydroxylation pathway \\
2-OHE1 \\
2-OHE2 \\
2-MeOE1 \\
4-Hydroxylation pathway \\
4-OHE1 \\
4-OHE2 \\
4-MeOE1 \\
16-Hydroxylation pathway \\
16 $\alpha$-OHE1 \\
Estriol \\
Total estrogens/estrogen metabolites
\end{tabular}

\begin{tabular}{c}
\hline Invasive breast cancer 50th $(25$ th, 75 th) \\
\hline $3.14(1.39,4.86)$ \\
$1.81(0.76,3.87)$ \\
$0.63(0.31,1.15)$ \\
$1.09(0.48,2.21)$ \\
$0.24(0.02,0.70)$ \\
$0.32(0.00,0.92)$ \\
$0.25(0.14,0.51)$ \\
$0.53(0.09,1.32)$ \\
$0.45(0.00,1.32)$ \\
$0.00(0.00,0.08)$ \\
$0.00(0.00,0.11)$ \\
$1.08(0.36,1.84)$ \\
$0.16(0.06,0.33)$ \\
$0.85(0.26,1.45)$ \\
$6.68(4.15,10.37)$
\end{tabular}

Breast fibroadenoma 50th (25th, 75th)

$4.45(2.93,9.20)$

$3.11(1.71,5.25)$

$1.54(0.92,3.45)$

$2.30(1.53,4.59)$

$0.83(0.46,1.87)$

$0.89(0.34,1.31)$

$0.41(0.26,0.71)$

$0.87(0.51,1.50)$

$0.44(0.24,0.81)$

$0.13(0.00,0.24)$

$0.07(0.00,0.25)$

$2.45(0.78,6.41)$

$0.58(0.23,1.89)$

$1.89(0.45,5.18)$

$12.15(6.86,24.53)$

\begin{tabular}{r}
\multicolumn{1}{c}{$\boldsymbol{P}$} \\
\hline 0.464 \\
0.488 \\
0.300 \\
$\mathbf{0 . 0 2 8}$ \\
$\mathbf{0 . 0 2 9}$ \\
$\mathbf{0 . 0 0 6}$ \\
0.071 \\
$\mathbf{0 . 0 2 7}$ \\
0.539 \\
$<\mathbf{0 . 0 0 1}$ \\
$<\mathbf{0 . 0 0 1}$ \\
0.297 \\
$<\mathbf{0 . 0 0 1}$ \\
0.979 \\
0.193
\end{tabular}

Bold indicates statistical significance, $P<0.05$

\section{Association between hormone receptor status and estrogen metabolism}

We next sought to determine the relationship between HR status and the levels of estrogen and their metabolites in premenopausal and postmenopausal patients (Table 4). In premenopausal patients with breast cancer, HR status was positively related to 2-OHE2 level $(P=0.028)$.
In contrast, there were no significant differences between HR status and all estrogen metabolites in postmenopausal patients (Supplementary Table 1, see section on supplementary materials given at the end of this article). ROC curve (Fig. 3) showed urinary 2-OHE2 had predictive value for HR status in premenopausal patients, with the optimal cutoffs of 0.21 .

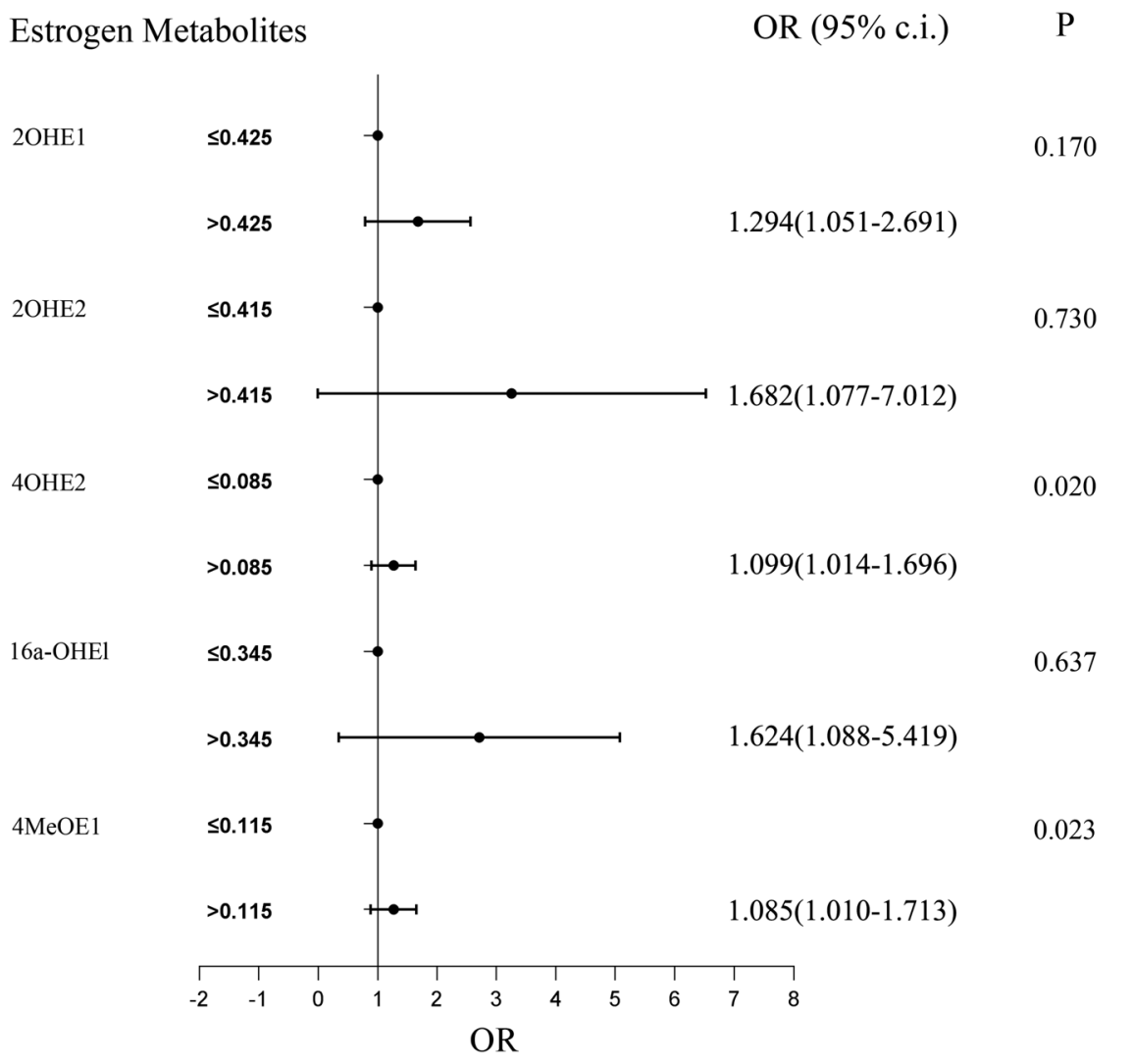

Figure 1

Forest plot of OR and $95 \% \mathrm{Cl}$ for estrogen metabolites. OR, odds ratios. https://ec.bioscientifica.com

https://doi.org/10.1530/EC-21-0226 (c) 2021 The authors Published by Bioscientifica Ltd

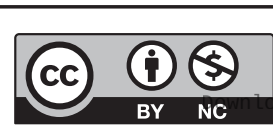

This work is licensed under a Creative Commons Attribution-NonCommercial 4.0 International License. ded from Bioscientifica.com at 04/26/2023 07:06:20AM via free access 

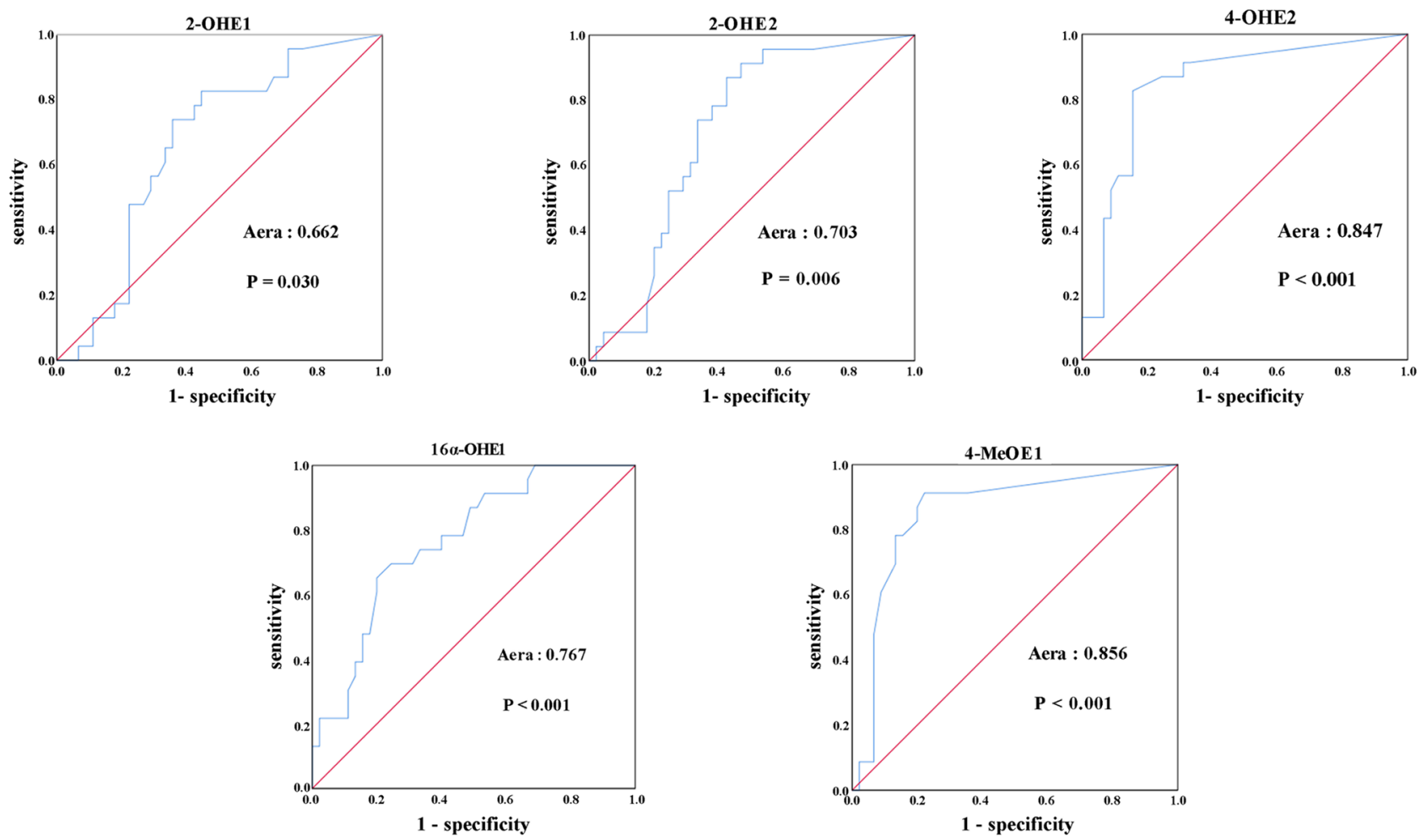

\section{Figure 2}

The ROC curve of urinary 2-OHE1 (area under curve $=0.662, P=0.03$ ), 2-OHE2 (area under curve $=0.703, P=0.006$ ), 4-OHE2 (area under curve $=0.847$, $P<0.001$ ), 4-MetOE1 (area under curve $=0.856, P<0.001$ ), and $16 \alpha$-OHE1 (area under curve $=0.767, P<0.001$ ) in postmenopausal patients.

\section{Discussion}

Estrogen metabolism is the cumulative interaction of multiple pathways under the catalytic activities of numerous estrogen metabolic enzymes, during which a variety of metabolites are produced. Since these metabolites exhibit pro- and antitumorigenic properties, an imbalance in the metabolites produced from these different metabolic pathways may lead to serious physiological changes and ultimately cancer. Therefore, understanding the estrogen metabolic pathways and exploring the mechanism of estrogen metabolism in tumorigenesis are of great

Table 4 Association between hormone receptor status and estrogen metabolism in premenopausal breast cancer patients.

\begin{tabular}{lll}
\hline Estrogens and estrogen metabolites & & HR- 50th $(25$ th, 75 th $)$ \\
\cline { 1 - 2 } Parent estrogens & & $7.10(4.61,11.35)$ \\
Estrone & & $5.06(3.02,6.13)$ \\
Estradiol & $2.97(1.59,5.22)$ \\
2-Hydroxylation pathway & & $2.64(1.51,3.56)$ \\
2-OHE1 & $1.97(0.38,2.79)$ \\
2-OHE2 & $0.00(0.00,0.08)$ \\
2-MeOE1 & $0.55(0.41,0.77)$ \\
4-Hydroxylation pathway & $0.07(0.00,0.40)$ \\
4-OHE1 & $0.07(0.00,0.40)$ \\
4-OHE2 & $0.00(0.00,0.07)$ \\
4-MeOE1 & $0.00(0.00,0.00)$ \\
16-Hydroxylation pathway & $3.43(2.38,5.64)$ \\
16 $\alpha$-OHE1 & $0.67(0.44,1.20)$ \\
Estriol & $2.71(1.64,5.25)$ \\
Total estrogens/estrogen metabolites & $15.99(10.23,21.28)$ \\
\hline
\end{tabular}

\begin{tabular}{ccc} 
HR+ 50th $(25$ th, 75 th $)$ & $\boldsymbol{P}$ \\
\hline $5.72(3.71,8.38)$ & & 0.382 \\
$3.85(2.57,4.85)$ & & 0.282 \\
$1.94(1.36,3.30)$ & & 0.365 \\
$1.64(1.21,3.73)$ & & 0.708 \\
$0.87(0.48,2.18)$ & & 0.606 \\
$0.28(0.00,0.55)$ & & $\mathbf{0 . 0 2 8}$ \\
$0.44(0.29,0.66)$ & & 0.288 \\
$0.44(0.16,0.94)$ & & 0.066 \\
$0.34(0.00,1.59)$ & & 0.145 \\
$0.32(0.03,0.88)$ & & 0.229 \\
$0.00(0.00,0.00)$ & & 0.101 \\
$3.22(1.87,5.87)$ & & 0.864 \\
$0.51(0.34,0.84)$ & 0.473 \\
$2.61(1.42,5.32)$ & 0.950 \\
$12.11(7.72,22.08)$ & 0.876
\end{tabular}

$\mathrm{HR}-$, hormone receptor negative breast cancer; $\mathrm{HR}+$, hormone receptor positive breast cancer. Bold indicates statistical significance, $P<0.05$.

https://ec.bioscientifica.com

https://doi.org/10.1530/EC-21-0226 (c) 2021 The authors Published by Bioscientifica Ltd

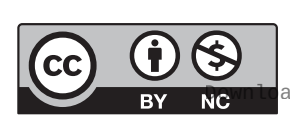

This work is licensed under a Creative Commons Attribution-NonCommercial 4.0 International License. ded from Bioscientifica.com at 04/26/2023 07:06:20AM 


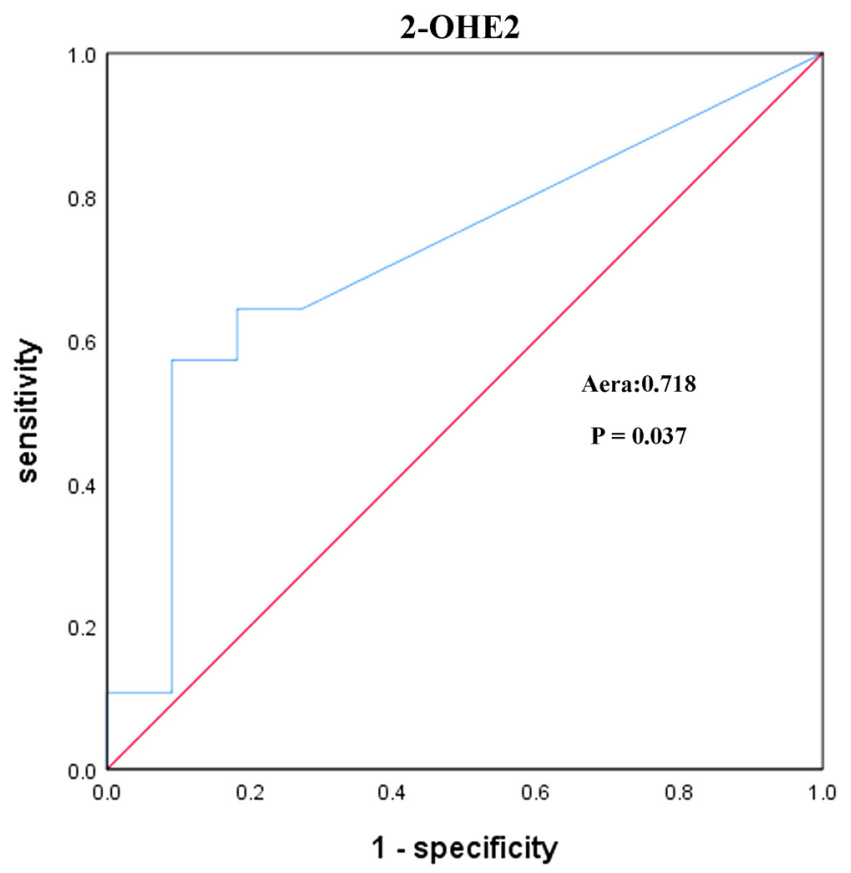

Figure 3

The ROC curve of urinary 2-OHE2 (area under curve $=0.718, P=0.037$ ) for hormone receptor status in premenopausal patients.

importance to the effective prevention and treatment of breast cancer.

Estrogen metabolism involves a homeostatic state of active and inactive pathways. Aromatization of androstenedione and testosterone is catalyzed by cytochrome P450 (CYP) enzymes, yielding E1 and E2, respectively $(28,29,30)$. Following the conversion from estradiol to estrone in the $\mathrm{C} 17$ position, hydroxylation occurs at the $\mathrm{C} 2, \mathrm{C} 4$, or $\mathrm{C} 16$ positions of estrone to form A-ring and D-ring metabolites (31), including 2-OHE1, 4-OHE1, 16 $\alpha$-OHE1, and estriol. Previous studies have found that 4-OHE1 has a longer half-life in vivo than 2-OHE1 and is more easily oxidized into quinones, which physically bind to DNA, increasing the probability of DNA replication errors, and therefore increasing the risk for the occurrence of breast cancer.

In this study, we used a rapid HPLC-MS/MS approach to accurately detect and quantify urinary estrogen and estrogen metabolites in patients diagnosed with breast cancer and benign breast disease (due to limited urinary samples from healthy controls). The urine samples of premenopausal and postmenopausal patients were also analyzed. We observed significantly lower levels of urinary 2-OHE2 in premenopausal patients with invasive breast cancer than in patients with breast fibroadenoma. In postmenopausal patients, there was a statistical difference in the levels of 2-OHE1, 2-OHE2, 4-OHE2, 4 -MeOE1, and 16 $\alpha$-OHE1 between both groups, showing these metabolites were considerably lower in the patients with breast cancer. The risk of developing breast cancer increased with a decline in the levels of 4-OHE2 and 4-MeOE1. Therefore, the correlation between the levels of estrogen metabolites and breast cancer risk was primarily analyzed in postmenopausal patients.

According to a comprehensive review, 4-OHE2 and $16 \alpha$-OHE1 are potential oncogenic molecular markers, 2-OHE1 and 2-OHE2 are primary estrogen metabolites, and estrogen methylation products, such as 2-MeOE1 and 4-MeOE1, are potential tumor suppressor molecular markers $(15,32,33,34,35,36,37,38)$. However, our results showed that the levels of 4-OHE2 (0.00 vs 0.13$)$ and $16 \alpha$ OHE1 (0.16 vs 0.58) were lower in the patients with breast cancer and that increased 4-OHE2 may inhibit progression of breast cancer. There are a number of possible reasons for this discrepancy: first, the concentrations of estrogens are comparatively low in postmenopausal Asian women, particularly in China, which may influence the results; secondly, the sample size is limited, and large-scale prospective clinical studies are needed to validate our results; thirdly, our analysis included benign controls, rather than a healthy group, which may be inconsistent with the association in the metabolite levels between a malignant and normal group.

Few studies have focused on the association of estrogen metabolites in urine and tumor HR status. This study revealed that in premenopausal patients, 2-OHE2 in HR+ patients was considerably higher than in HR- patients, suggesting that the levels of 2-OHE2 could have different effects on $\mathrm{HR}+$ and $\mathrm{HR}$ - breast cancers. Additionally, 2-OHE2 had predictive value for HE status for breast cancer patients, which was potentially attributed to the hypothesis that 2-OHE2 could promote HR+ breast cancer by binding with the HR to enhance nuclear mitosis of tumor cells. However, in postmenopausal patients, there was no difference between HR+ and HR- patients in estrogen and estrogen metabolites.

In summary, estrogen metabolism was associated with breast cancer risk in both premenopausal and postmenopausal women, and the level of 2-OHE2 could be an important factor for HR+ breast cancer.

Supplementary materials

This is linked to the online version of the paper at https://doi.org/10.1530/ EC-21-0226. 
Endocrinology 2006147 4132-4150. (https://doi.org/10.1210/en.20060113)

The authors declare that there is no conflict of interest that could be perceived as prejudicing the impartiality of the research reported.

\section{Funding}

This study was funded by Science and Technology Department of Sichuan Province (No. 2019YFS0377); 1.3.5 project for disciplines of excellence, West China Hospital, Sichuan University (No. ZYJC21082).

\section{References}

1 DeSantis CE, Ma J, Gaudet MM, Newman LA, Miller KD, Goding Sauer A, Jemal A \& Siegel RL. Breast cancer statistics, 2019. CA: A Cancer Journal for Clinicians 201969 438-451. (https://doi.org/10.3322/ caac.21583)

2 Ziegler RG, Anderson WF \& Gail MH. Increasing breast cancer incidence in China: the numbers add up. Journal of the National Cancer Institute 2008100 1339-1341. (https://doi.org/10.1093/jnci/ djn330)

3 Cavalieri E, Chakravarti D, Guttenplan J, Hart E, Ingle J, Jankowiak R, Muti P, Rogan E, Russo J, Santen R, et al. Catechol estrogen quinones as initiators of breast and other human cancers: implications for biomarkers of susceptibility and cancer prevention. Biochimica et Biophysica Acta 20061766 63-78. (https://doi.org/10.1016/j. bbcan.2006.03.001)

4 Lavigne JA, Goodman JE, Fonong T, Odwin S, He P, Roberts DW \& Yager JD. The effects of catechol-O-methyltransferase inhibition on estrogen metabolite and oxidative DNA damage levels in estradioltreated MCF-7 cells. Cancer Research 200161 7488-7494.

5 IARC Working Group on the Evaluation of Carcinogenic Risks to Humans. Combined estrogen-progestogen contraceptives and combined estrogen-progestogen menopausal therapy. IARC Monographs on the Evaluation of Carcinogenic Risks to Humans 200791 1-528.

6 Bernstein L \& Ross RK. Endogenous hormones and breast cancer risk. Epidemiologic Reviews 199315 48-65. (https://doi.org/10.1093/ oxfordjournals.epirev.a036116)

7 Key TJ \& Pike MC. The role of oestrogens and progestagens in the epidemiology and prevention of breast cancer. European Journal of Cancer and Clinical Oncology 198824 29-43. (https://doi. org/10.1016/0277-5379(88)90173-3)

8 Yager JD \& Davidson NE. Estrogen carcinogenesis in breast cancer. New England Journal of Medicine 2006354 270-282. (https://doi. org/10.1056/NEJMra050776)

9 Schneider J, Huh MM, Bradlow HL \& Fishman J. Antiestrogen action of 2-hydroxyestrone on MCF-7 human breast cancer cells. Journal of Biological Chemistry 1984259 4840-4845. (https://doi.org/10.1016/ S0021-9258(17)42922-X)

10 Vandewalle B \& Lefebvre J. Opposite effects of estrogen and catecholestrogen on hormone-sensitive breast cancer cell growth and differentiation. Molecular and Cellular Endocrinology 198961 239-246. (https://doi.org/10.1016/0303-7207(89)90135-4)

11 Swaneck GE \& Fishman J. Covalent binding of the endogenous estrogen 16 alpha-hydroxyestrone to estradiol receptor in human breast cancer cells: characterization and intranuclear localization. PNAS 198885 7831-7835. (https://doi.org/10.1073/pnas.85.21.7831)

12 Seeger H, Wallwiener D, Kraemer E \& Mueck AO. Comparison of possible carcinogenic estradiol metabolites: effects on proliferation, apoptosis and metastasis of human breast cancer cells. Maturitas 2006 54 72-77. (https://doi.org/10.1016/j.maturitas.2005.08.010)

13 Zhu BT, Han GZ, Shim JY, Wen Y \& Jiang XR. Quantitative structureactivity relationship of various endogenous estrogen metabolites for human estrogen receptor alpha and beta subtypes: insights into the structural determinants favoring a differential subtype binding.
14 Kono S, Merriam GR, Brandon DD, Loriaux DL, Lipsett MB \& Fujino T. Radioimmunoassay and metabolic clearance rate of catecholestrogens, 2-hydroxyestrone and 2-hydroxyestradiol in man. Journal of Steroid Biochemistry 198319 627-633. (https://doi.org/10.1016/00224731(83)90228-5)

15 Cavalieri E, Frenkel K, Liehr JG, Rogan E \& Roy D. Estrogens as endogenous genotoxic agents - DNA adducts and mutations. Journal of the National Cancer Institute: Monographs 200027 75-93. (https://doi. org/10.1093/oxfordjournals.jncimonographs.a024247)

16 Yucel K, Abusoglu S \& Unlu A. Comparison of immunoassay and liquid chromatography-tandem mass spectrometry methods in the measurement of serum androstenedione levels. Clinical Laboratory 201864 69-75. (https://doi.org/10.7754/Clin.Lab.2017.170612)

17 Faupel-Badger JM, Fuhrman BJ, Xu X, Falk RT, Keefer LK, Veenstra TD, Hoover RN \& Ziegler RG. Comparison of liquid chromatographytandem mass spectrometry, RIA, and ELISA methods for measurement of urinary estrogens. Cancer Epidemiology, Biomarkers and Prevention 201019 292-300. (https://doi.org/10.1158/1055-9965.EPI-09-0643)

18 Bradlow HL, Sepkovic DW, Klug T \& Osborne MP. Application of an improved ELISA assay to the analysis of urinary estrogen metabolites. Steroids 199863 406-413. (https://doi.org/10.1016/s0039$128 \times(98) 00041-5)$

19 McGuinness BJ, Power MJ \& Fottrell PF. Radioimmunoassay of 2-hydroxyestrone in urine. Clinical Chemistry 199440 80-85. (https:// doi.org/10.1093/clinchem/40.1.80)

20 Franke AA, Custer LJ, Morimoto Y, Nordt FJ \& Maskarinec G. Analysis of urinary estrogens, their oxidized metabolites, and other endogenous steroids by benchtop Orbitrap LCMS versus traditional quadrupole GCMS. Analytical and Bioanalytical Chemistry 2011401 1319-1330. (https://doi.org/10.1007/s00216-011-5164-3)

21 Guo T, Gu J, Soldin OP, Singh RJ \& Soldin SJ. Rapid measurement of estrogens and their metabolites in human serum by liquid chromatography-tandem mass spectrometry without derivatization. Clinical Biochemistry 200841 736-741. (https://doi.org/10.1016/j. clinbiochem.2008.02.009)

22 Gao WL, Wu LS, Zi JH, Wu B, Li YZ, Song YC \& Cai DZ. Measurement of serum estrogen and estrogen metabolites in pre- and postmenopausal women with osteoarthritis using high-performance liquid chromatography-electrospray ionization-tandem mass spectrometry. Brazilian Journal of Medical and Biological Research 2015 48 146-153. (https://doi.org/10.1590/1414-431X20144129)

23 Carvalho VM. The coming of age of liquid chromatography coupled to tandem mass spectrometry in the endocrinology laboratory. Journal of Chromatography: B, Analytical Technologies in the Biomedical and Life Sciences 2012 883-884 50-58. (https://doi.org/10.1016/j. jchromb.2011.08.027)

24 Rothman MS, Carlson NE, Xu M, Wang C, Swerdloff R, Lee P, Goh VH, Ridgway EC \& Wierman ME. Reexamination of testosterone, dihydrotestosterone, estradiol and estrone levels across the menstrual cycle and in postmenopausal women measured by liquid chromatography-tandem mass spectrometry. Steroids 2011 76 177-182. (https://doi.org/10.1016/j.steroids.2010.10.010)

25 Xu X, Roman JM, Issaq HJ, Keefer LK, Veenstra TD \& Ziegler RG. Quantitative measurement of endogenous estrogens and estrogen metabolites in human serum by liquid chromatography-tandem mass spectrometry. Analytical Chemistry 200779 7813-7821. (https://doi. org/10.1021/ac070494j)

26 Xu X, Veenstra TD, Fox SD, Roman JM, Issaq HJ, Falk R, Saavedra JE, Keefer LK \& Ziegler RG. Measuring fifteen endogenous estrogens simultaneously in human urine by high-performance liquid chromatography-mass spectrometry. Analytical Chemistry $20057 \mathbf{7}$ 6646-6654. (https://doi.org/10.1021/ac050697c)

27 You J, Shi Y, Li J, Yang X, Liu Z, Zhu W, Wu Z \& Xiong J. Rapid quantification of human urinary estrogens and estrogen metabolites https://ec.bioscientifica.com https://doi.org/10.1530/EC-21-0226 (c) 2021 The authors Published by Bioscientifica Ltd
This work is licensed under a Creative Commons Attribution-NonCommercial 4.0 International License. ded from Bioscientifica.com at 04/26/2023 07:06:20AM 
by HPLC mass spectrometry. Microchemical Journal 2019147 157-162. (https://doi.org/10.1016/j.microc.2019.03.008)

28 Jefcoate CR, Liehr JG, Santen RJ, Sutter TR, Yager JD, Yue W, Santner SJ Tekmal R, Demers L, Pauley R, et al. Tissue-specific synthesis and oxidative metabolism of estrogens. Journal of the National Cancer Institute: Monographs 200027 95-112. (https://doi.org/10.1093/ oxfordjournals.jncimonographs.a024248)

29 Liehr JG. Is estradiol a genotoxic mutagenic carcinogen? Endocrine Reviews 200021 40-54. (https://doi.org/10.1210/edrv.21.1.0386)

30 Hayes CL, Spink DC, Spink BC, Cao JQ, Walker NJ \& Sutter TR. 17betaEstradiol hydroxylation catalyzed by human cytochrome P450. PNAS 199693 9776-9781. (https://doi.org/10.1073/pnas.93.18.9776)

31 Lippert TH, Seeger H \& Mueck AO. Metabolism of Endogenous Estrogens. Estrogens and Antiestrogens I. Berlin, Heidelberg: Springer, 1999 (https://doi.org/10.1007/978-3-642-58616-3_12)

32 Bradlow HL, Hershcopf RJ, Martucci CP \& Fishman J. Estradiol 16 alpha-hydroxylation in the mouse correlates with mammary tumor incidence and presence of murine mammary tumor virus: a possible model for the hormonal etiology of breast cancer in humans. PNAS 198582 6295-6299. (https://doi.org/10.1073/pnas.82.18.6295)

33 Telang NT, Bradlow HL, Kurihara H \& Osborne MP. In vitro biotransformation of estradiol by explant cultures of murine mammary tissues. Breast Cancer Research and Treatment 198913 173-181. (https://doi.org/10.1007/BF01806529)

34 Yager JD \& Liehr JG. Molecular mechanisms of estrogen carcinogenesis. Annual Review of Pharmacology and Toxicology 199636 203-232. (https://doi.org/10.1146/annurev.pa.36.040196.001223)

35 Zhu BT \& Conney AH. Is 2-methoxyestradiol an endogenous estrogen metabolite that inhibits mammary carcinogenesis? Cancer Research 199858 2269-2277.

36 Kabat GC, Chang CJ, Sparano JA, Sepkovie DW, Hu XP, Khalil A, Rosenblatt R \& Bradlow HL. Urinary estrogen metabolites and breast cancer: a case-control study. Cancer Epidemiology, Biomarkers and Prevention 19976 505-509.

37 Meilahn EN, De Stavola B, Allen DS, Fentiman I, Bradlow HL, Sepkovic DW \& Kuller LH. Do urinary oestrogen metabolites predict breast cancer? Guernsey III cohort follow-up. British Journal of Cancer 199878 1250-1255. (https://doi.org/10.1038/bjc.1998.663)

38 Muti P, Bradlow HL, Micheli A, Krogh V, Freudenheim JL, Schünemann HJ, Stanulla M, Yang J, Sepkovic DW, Trevisan M, et al. Estrogen metabolism and risk of breast cancer: a prospective study of the 2:16alpha-hydroxyestrone ratio in premenopausal and postmenopausal women. Epidemiology 200011 635-640. (https://doi. org/10.1097/00001648-200011000-00004)

Received in final form 19 October 2021

Accepted 22 November 2021

Accepted Manuscript published online 23 November 2021 https://ec.bioscientifica.com

https://doi.org/10.1530/EC-21-0226 (c) 2021 The authors Published by Bioscientifica Ltd
This work is licensed under a Creative Commons Attribution-NonCommercial 4.0 International License. ded from Bioscientifica.com at 04/26/2023 07:06:20AM 